University of Nebraska - Lincoln

DigitalCommons@University of Nebraska - Lincoln

US Army Research

U.S. Department of Defense

2012

Disability among US Army Veterans vaccinated against anthrax

\author{
Sandra I. Sulsky \\ ENVIRON International Corporation, ssulsky@environcorp.com \\ Rose Luippold \\ ENVIRON International Corporation \\ Patrick Garman \\ Military Vaccine Agency \\ Hayley Hughes \\ Military Vaccine Agency \\ Edward J. Boyko \\ University of Washington \\ See next page for additional authors
}

Follow this and additional works at: https://digitalcommons.unl.edu/usarmyresearch

Sulsky, Sandra I.; Luippold, Rose; Garman, Patrick; Hughes, Hayley; Boyko, Edward J.; Maynard, Charles; and Amoroso, Paul J., "Disability among US Army Veterans vaccinated against anthrax" (2012). US Army Research. 227.

https://digitalcommons.unl.edu/usarmyresearch/227

This Article is brought to you for free and open access by the U.S. Department of Defense at DigitalCommons@University of Nebraska - Lincoln. It has been accepted for inclusion in US Army Research by an authorized administrator of DigitalCommons@University of Nebraska - Lincoln. 


\section{Authors}

Sandra I. Sulsky, Rose Luippold, Patrick Garman, Hayley Hughes, Edward J. Boyko, Charles Maynard, and Paul J. Amoroso 


\title{
Disability among US Army Veterans vaccinated against anthrax ${ }^{\text {is }}$
}

\author{
Sandra I. Sulsky ${ }^{\mathrm{a}, *}$, Rose Luippold ${ }^{\mathrm{a}}$, Patrick Garman ${ }^{\mathrm{b}}$, Hayley Hughes ${ }^{\mathrm{b}}$, Edward J. Boyko ${ }^{\mathrm{c}}$, \\ Charles Maynard ${ }^{\mathrm{c}}$, Paul J. Amoroso ${ }^{\mathrm{d}}$
}

a ENVIRON International Corporation, Amherst, MA 01002, United States

b Office of the Surgeon General of the Army, Military Vaccine Agency, United States

${ }^{c}$ VA Puget Sound Health Care System and the University of Washington, United States

d MultiCare Institute for Research and Innovation, Tacoma, WA, United States

\section{A R T I C L E I N F O}

\section{Article history:}

Received 10 April 2012

Received in revised form 18 July 2012

Accepted 25 July 2012

Available online 5 August 2012

\section{Keywords}

Vaccine safety

Military

Veterans

Epidemiology

\begin{abstract}
A B S T R A C T
Context: To protect troops against the use of anthrax as a biological weapon, the US Department of Defense began an anthrax vaccination program in 1998. 14 years after the inception of the vaccination program, there is no evidence suggesting vaccination against anthrax carries long-term health risks for Active Duty Soldiers.

Objective: To investigate the association between Anthrax Vaccine Adsorbed (AVA) received while on Active Duty and subsequent disability determined by the Veterans Benefits Administration.

Design, setting and participants: Case-control study nested in the cohort of all Active Duty personnel known to have separated from the US Army between December 1, 1997 and December 31, 2005. Cases were $\geq 10 \%$ disabled, determined either by the Army prior to separation $(N=5846)$ or by the Veterans Benefits Administration (VBA) after separation $(N=148,934)$. Controls $(N=937,705)$ separated from the Army without disability, and were not receiving pensions from the VBA as of April 2007. Data were from the Total Army Injury and Health Outcomes Database and the VBA Compensation and Pension and Benefits database.

Main outcomes: Disability status (yes/no); for primary disability, percent disabled ( $\geq 10 \%, 20 \%,>20 \%$ ) and type of disability.

Results: Vaccination against anthrax was four times more likely among disabled Veterans with hostile fire pay records (HFP, a surrogate for deployment). Vaccinated Soldiers with HFP had lower odds of disability separation from the Army 0.89 (0.80, 0.98); there was no association between vaccine and receiving Army disability benefits among those without $\operatorname{HFP}(\mathrm{OR}=1.05, \mathrm{CI}: 0.96,1.14)$. Vaccination was negatively associated with receiving VA disability benefits for those with $\mathrm{HFP}(\mathrm{OR}=0.66, \mathrm{CI}: 0.65,0.67)$, but there was little or no association between vaccine and receipt of VA disability benefits for those without HFP (OR=0.95, CI: 0.93, 0.97).

Conclusions: Risk of disability separation from the Army and receipt of disability compensation from the VA were not increased in association with prior exposure to AVA. This study provides evidence that vaccination against anthrax is not associated with long term disability.
\end{abstract}

(c) 2012 Elsevier Ltd. All rights reserved.
Anthrax is a zoonotic disease caused by Bacillus anthracis that may affect humans who handle the hide or wool of grazing animals or work with live animals. Because of its stability and virulence, the low rate of natural immunity in humans, and the ease with which it can be aerosolized and deployed as a weapon, the US Department of Defense identified $B$. anthracis as a threat to US troops, and initiated an anthrax vaccination program in 1998 [1-3] that prioritized

\footnotetext{
Disclaimer: The opinions or assertions contained herein are the private views of the author(s) and are not to be construed as official or as reflecting the views of the Army, the VBA Department of Veterans Affairs or the Department of Defense.

* Corresponding author. Tel.: +1 4132563556.

E-mail address: ssulsky@environcorp.com (S.I. Sulsky).
}

individuals about to be deployed to regions deemed to be at a higher threat for exposure to weaponized anthrax [4].

The frequency and severity of immediate adverse events associated with Anthrax Vaccine Adsorbed (AVA) are similar to those associated with other adult vaccines, and no study has produced evidence of increased risk of any lasting condition associated with AVA [5-13]. In spite of its demonstrated safety and effectiveness, worries about potential long term effects persist [3,14,15]. Studies restricted to Active Duty Soldiers have the benefit of providing nearly complete data on both vaccination status and health outcomes because they can be based on routinely collected health care records from a relatively closed system, and thus are not subject to selection bias. Adverse vaccine events may be under-counted, however, if either their recognition or development is delayed past 
Table 1

Inclusion and exclusion criteria.

\begin{tabular}{lrr}
\hline Criterion & N Excluded & N Remaining \\
\hline US Army Active Duty between 12/1/1997 & & $1,014,998$ \\
$\quad$ and 12/31/2005 & & \\
Invalid vaccination date (prior to 3/1998) & 643 & $1,014,355$ \\
Age at entry into Army <17 or >34 years ${ }^{\mathrm{b}}$ & 1418 & $1,012,937$ \\
$\quad$ No date of separation & 0 & $1,012,937$ \\
Duration of service $\leq 91.3$ days $^{\mathrm{c}}$ & 40,775 & 972,162 \\
Deceased prior to separation from service & 21 & 972,141 \\
Disability determined by both APDA and $^{\text {VBA }}$ & 30,354 & 941,787 \\
APDA Analysis $^{\mathrm{e}}$ & & \\
VBA Analysis $^{\mathrm{f}}$ & 153,016 & 788,771 \\
\hline
\end{tabular}

a Study start and end dates.

b Suggests unreliable data.

c To exclude disability due to injuries sustained in basic combat training.

d APDA = Army Physical Disability Agency. VBA = Veteran's Benefits Administration.

e Includes all controls and ADPA cases with complete information on relevant covariates.

${ }^{\mathrm{f}}$ Includes all controls and VBA cases with complete information on relevant covariates.

the time of separation from Service, or if Soldiers choose not to report potential problems. To address these limitations, we conducted a nested case-control study to determine if vaccination against anthrax during Active Duty is associated with subsequent receipt of disability compensation through the Veterans Benefits Administration (VBA). Separated Service Members are entitled to seek disability compensation, health and other benefits from the VBA and the Veterans Health Administration. Disability compensation may be awarded for problems that manifest after military service if the problem can be documented as having originated during Service, or if an established association exists with a military exposure, e.g., Agent Orange exposure and later development of diabetes [16].

\section{Methods}

Data were obtained from the Total Army Injury and Health Outcomes Database (TAIHOD), which links occupational and demographic data from the Defense Manpower Data Center (DMDC) with information from the Army Physical Disability Agency (APDA), among others, for all Active Duty US Army Soldiers [17]. Anthrax vaccination data were obtained from the Military Vaccine (MILVAX) Agency. The VBA identified individuals receiving disability benefits, along with reason for and percentage disability, and death dates for those who were deceased as of April 2007. The protocol for this study was reviewed and approved by the Institutional Review Boards of ENVIRON International Corporation, the Army Research Institute of Environmental Medicine, the Army Medical Research and Materiel Command and the Human Subjects Division of the University of Washington.

The cohort consists of all Soldiers on Active Duty between December 1, 1997 and February 1, 2005. For each individual, we abstracted the earliest data available from up to 18 semi-annual DMDC updates and retained the earliest and latest recorded dates of entry into, and separation from, the Army. Follow-up began with the date of entry into the Army or the start of the study, whichever came last, and ended with separation from Service, first disability finding by the APDA, death, or the end of the study, whichever came first. Reasons for exclusions and counts of excluded Soldiers are shown in Table 1.

We separately analyzed two case series: those who received disability ratings $\geq 10 \%$ and were discharged from the Active Duty Army after formal evaluation by the ADPA ("APDA cases"), and those with disability ratings of $\geq 10 \%$ and receiving disability compensation from the VBA ("VBA cases") subsequent to discharge from the Army in April 2007. Both case series were compared to the same controls, allowing for direct comparison of determinants of risk for each. Controls comprise Soldiers who had separated from Service, had never been evaluated for or granted disability by the APDA during Active Duty and were alive and not receiving VBA compensation on the data extraction date.

Disabilities were classified according to the Veterans Administration Schedule for Rating Disability (VASRD) by both the APDA and the VBA, allowing all cases to be classified according to primary reason for and percent disability, and body system affected. Musculoskeletal disabilities were categorized according to likelihood of being of traumatic or non-traumatic origin. Exposure status was determined by receipt of at least one dose of AVA during Active Duty, delivered between March 1998 and December 31, 2005.

\subsection{Statistical methods}

Data analyses were completed using SAS version 9.1 [18]. We identified possible confounders separately for the two case-control comparisons by identifying the covariates that were associated with both exposure and outcome. We used logistic regression analysis to estimate the odds of disability by AVA exposure and $95 \%$ confidence intervals $(95 \% \mathrm{CI}$ ) for each case series versus controls. Initial two-term models included a vaccination indicator and each covariate that caused $\geq 10 \%$ change in estimated odds of disability with vaccination status. Each remaining covariate was added individually, and we retained covariates that changed the vaccination estimate for the disability odds ratio $\geq 5 \%$. Interactions were identified by examining whether effect estimates differed across strata defined by covariates. No statistical testing was used to identify interactions because the large number of observations leads to a high likelihood of identifying small magnitude differences as statistically significant. The goodness of fit of final multiple logistic regression models was evaluated using the Hosmer-Lemeshow Goodness of Fit test and discrimination was evaluated with the c-statistic.

\section{Results}

After applying inclusion and exclusion criteria (Table 1), there were 782,925 controls, 148,934 VBA cases and 5846 APDA cases eligible for analysis; the VBA and APDA cases were mutually exclusive. We excluded an additional 30,354 cases designated disabled by both the ADPA and the VBA. These records would not be informative for identification of differences in cases identified by the two agencies, because they were identified by both. They also were included as cases in a prior cohort study [19].

The proportion of vaccinated individuals was similar for the two case series, but higher for the controls (Table 2). Each case series had higher proportions of women compared to the controls. The VBA cases compared to APDA cases and controls were more likely to be Black, better educated, and to have achieved higher pay grade while in service. VBA cases served about twice as long as controls, and more than 2.5 times longer than APDA cases. Controls were more likely to have received hostile fire pay, a marker for deployment, than either the APDA or VBA cases. Controls were followed for a mean (standard deviation) of 4.1 (2.7) years, APDA cases for 2.9 (2.1) years, and VBA cases for 3.9 (2.4) years (Table 2).

Within controls and each case group, AVA status varied by covariates (Tables 3a and 3b). Among VBA cases and controls, a higher proportion of men were vaccinated versus unvaccinated, while the reverse was true for women. Vaccination status among VBA cases was also associated with longer duration of followup, longer duration of service and pay grade, with higher ranking 
Table 2

Distribution of covariates by case and control status: mean and standard deviation (SD) or percent.

\begin{tabular}{|c|c|c|c|}
\hline$n=937,705$ & $\begin{array}{l}\text { Controls }^{\mathrm{a}} \\
(n=782,925)\end{array}$ & $\begin{array}{l}\text { APDA cases }^{\mathrm{a}} \\
(n=5846)\end{array}$ & $\begin{array}{l}\text { VBA cases }^{\mathrm{a}} \\
(n=148,934)\end{array}$ \\
\hline \multicolumn{4}{|l|}{ Vaccinated } \\
\hline Yes & 46.1 & 34.2 & 36.0 \\
\hline No & 53.9 & 65.8 & 64.0 \\
\hline \multicolumn{4}{|l|}{ Age (years) } \\
\hline Mean (SD) & $20.2(3.0)$ & $20.4(3.2)$ & $20.5(3.3)$ \\
\hline \multicolumn{4}{|l|}{ Gender } \\
\hline Men & 84.4 & 79.3 & 80.7 \\
\hline Women & 15.6 & 20.7 & 19.3 \\
\hline \multicolumn{4}{|l|}{ Race } \\
\hline White & 62.6 & 67.8 & 57.0 \\
\hline Black & 22.0 & 21.8 & 29.4 \\
\hline Hispanic & 9.3 & 6.9 & 7.6 \\
\hline Other & 6.2 & 4.4 & 6.1 \\
\hline \multicolumn{4}{|l|}{ Education $^{\mathrm{b}}$} \\
\hline$\leq$ High school & 97.3 & 98.0 & 90.8 \\
\hline$>$ High school & 2.7 & 2.0 & 9.2 \\
\hline \multicolumn{4}{|l|}{ Marital status ${ }^{\mathrm{b}}$} \\
\hline Married & 32.0 & 65.5 & 42.2 \\
\hline Unmarried & 68.0 & 34.5 & 57.8 \\
\hline \multicolumn{4}{|l|}{ Pay grade ${ }^{\mathrm{b}}$} \\
\hline E1-E3 & 60.9 & 66.1 & 32.2 \\
\hline E4-E6 & 25.4 & 29.2 & 33.6 \\
\hline E7-E9 & 2.5 & 1.5 & 20.0 \\
\hline Officers $^{\mathrm{c}}$ & 11.3 & 3.3 & 14.2 \\
\hline \multicolumn{4}{|c|}{ Duration follow-up mean (years) } \\
\hline Mean (SD) & $4.1(2.7)$ & $2.9(2.1)$ & $3.9(2.4)$ \\
\hline \multicolumn{4}{|c|}{ Years duration of service mean (years) ${ }^{b}$} \\
\hline Mean (SD) & $7.3(6.5)$ & $5.7(5.0)$ & $13.7(9.1)$ \\
\hline \multicolumn{4}{|l|}{ Hostile fire pay } \\
\hline Ever & 48.3 & 31.4 & 37.1 \\
\hline Never & 51.8 & 68.7 & 62.9 \\
\hline \multicolumn{4}{|l|}{ Major command code } \\
\hline $\begin{array}{l}\text { U.S. Army Forces } \\
\text { Command }\end{array}$ & 23.8 & 26.9 & 29.7 \\
\hline Training and Doctrine & 49.6 & 50.6 & 32.3 \\
\hline V Corps (Europe) & 5.0 & 4.9 & 5.7 \\
\hline Medical Command & 4.8 & 4.9 & 6.4 \\
\hline 8th U.S. Army & 3.2 & 2.9 & 4.1 \\
\hline U.S. Army Pacific & 2.2 & 2.1 & 2.9 \\
\hline Special Operations & 1.5 & 1.5 & 2.5 \\
\hline Signal Command & 0.8 & 0.9 & 1.5 \\
\hline Intelligence and security & 0.7 & 0.5 & 1.4 \\
\hline Other & 8.4 & 4.8 & 13.5 \\
\hline \multicolumn{4}{|l|}{ Year follow-up ended } \\
\hline$<1999$ & 6.9 & 13.3 & 11.7 \\
\hline 1999 & 6.0 & 12.8 & 10.1 \\
\hline 2000 & 6.0 & 12.0 & 10.3 \\
\hline 2001 & 6.4 & 9.6 & 11.0 \\
\hline 2002 & 5.8 & 7.3 & 10.2 \\
\hline 2003 & 5.6 & 8.6 & 10.7 \\
\hline 2004 & 6.4 & 11.3 & 14.4 \\
\hline 2005 & 56.8 & 25.0 & 21.7 \\
\hline
\end{tabular}

a VBA cases: Veterans receiving benefits from the Veterans Benefits Administration as of February 2007; APDA cases: Soldiers determined disabled during Active Duty by the Army Physical Disability Agency; Controls: Veterans without disability and with known date of separation from the Army. Case and control categories are mutually exclusive.

b Assessed at the beginning of follow-up.

c E1-E9: enlisted pay grades. Officers includes Warrant and commissioned officers.
Table 3a

Distribution of covariates by vaccination status for VBA cases ${ }^{\mathrm{a}}$ and controls ${ }^{\mathrm{b}}$ : mean and standard deviation (SD) or percent.

\begin{tabular}{|c|c|c|}
\hline $\begin{array}{l}\text { A: VBA cases and controls }{ }^{\mathrm{a}, \mathrm{b}} \\
(n=931,859)\end{array}$ & $\begin{array}{l}\text { Never vaccinated } \\
(n=517,333)\end{array}$ & $\begin{array}{l}\text { Vaccinated } \\
(n=414,526)\end{array}$ \\
\hline \multicolumn{3}{|l|}{ Age (years) } \\
\hline Mean (SD) & $20.3(3.1)$ & $20.2(3.0)$ \\
\hline \multicolumn{3}{|l|}{ Gender } \\
\hline Men & 81.0 & 87.3 \\
\hline Women & 19.0 & 12.7 \\
\hline \multicolumn{3}{|l|}{ Race } \\
\hline White & 63.1 & 59.9 \\
\hline Black & 22.4 & 24.1 \\
\hline Hispanic & 8.5 & 9.7 \\
\hline Other & 6.0 & 6.3 \\
\hline \multicolumn{3}{|l|}{ Education $^{\mathrm{c}}$} \\
\hline$\leq$ High school & 95.9 & 96.7 \\
\hline$>$ High school & 4.1 & 3.3 \\
\hline \multicolumn{3}{|l|}{ Marital status ${ }^{\mathrm{c}}$} \\
\hline Married & 37.5 & 34.5 \\
\hline Unmarried & 62.5 & 65.5 \\
\hline \multicolumn{3}{|l|}{ Pay grade ${ }^{c}$} \\
\hline E1-E3 & 54.9 & 58.0 \\
\hline E4-E6 & 26.4 & 27.1 \\
\hline E7-E9 & 6.8 & 3.4 \\
\hline Officers $^{\mathrm{d}}$ & 12.0 & 11.5 \\
\hline \multicolumn{3}{|c|}{ Duration of active duty follow-up (years) } \\
\hline Mean (SD) & $3.1(2.4)$ & $5.3(2.3)$ \\
\hline \multicolumn{3}{|l|}{ Duration of service (years) ${ }^{c}$} \\
\hline Mean (SD) & $7.8(7.8)$ & $8.9(6.8)$ \\
\hline \multicolumn{3}{|l|}{ Hostile fire pay } \\
\hline Ever & 26.5 & 78.0 \\
\hline Never & 73.5 & 22.0 \\
\hline \multicolumn{3}{|l|}{ Major command code $\mathrm{c}^{\mathrm{C}}$} \\
\hline U.S. Army Forces Command & 23.7 & 26.0 \\
\hline Training and Doctrine & 45.6 & 48.5 \\
\hline V Corps (Europe) & 5.1 & 5.1 \\
\hline Medical Command & 6.1 & 3.7 \\
\hline 8th U.S. Army & 3.1 & 3.7 \\
\hline U.S. Army Pacific & 2.7 & 1.7 \\
\hline Special Operations & 1.4 & 2.0 \\
\hline Signal Command & 1.0 & 0.8 \\
\hline Intelligence and Security & 1.1 & 0.6 \\
\hline Other & 10.2 & 7.9 \\
\hline \multicolumn{3}{|l|}{ Year follow-up ended } \\
\hline$<1999$ & 13.6 & 0.2 \\
\hline 1999 & 10.2 & 2.2 \\
\hline 2000 & 9.3 & 3.4 \\
\hline 2001 & 9.5 & 4.2 \\
\hline 2002 & 9.1 & 3.3 \\
\hline 2003 & 7.1 & 5.6 \\
\hline 2004 & 6.2 & 9.6 \\
\hline 2005 & 35.0 & 71.4 \\
\hline
\end{tabular}

enlisted personnel (E7-E9) least likely to have been vaccinated prior to separation compared to officers, E4-E6 grade or E1-E3 grade. Seventy-eight percent of vaccinated versus $26.5 \%$ of unvaccinated Veterans had ever received hostile fire pay (HFP). Vaccination status did not vary notably by age, race-ethnicity, educational attainment or major command (Table 3a). There were similar patterns of prior vaccination among categories of APDA cases and controls (Table $3 \mathrm{~b}$ ).

Receipt of hostile fire pay, a marker for deployment, is strongly and inversely associated with receipt of disability benefits from the VA and risk of disability separation from the Army (Table 4a). Because of the policy that placed Soldiers deployed to high threat locations at higher priority for vaccination against anthrax, there is also a strong association between AVA exposure and receipt of 
Table 3b

Distribution of covariates by vaccination status for APDA cases ${ }^{\mathrm{a}}$ and controls ${ }^{\mathrm{b}}$ : mean and standard deviation (SD) or percent.

\begin{tabular}{|c|c|c|}
\hline $\begin{array}{l}\text { APDA cases and controls } \\
(n=788,771)\end{array}$ & $\begin{array}{l}\text { Never vaccinated } \\
(n=425,796)\end{array}$ & $\begin{array}{l}\text { Vaccinated } \\
(n=362,975)\end{array}$ \\
\hline \multicolumn{3}{|l|}{ Age (years) } \\
\hline Mean (SD) & $20.3(3.0)$ & $20.2(3.0)$ \\
\hline \multicolumn{3}{|l|}{ Gender } \\
\hline Men & 81.4 & 87.9 \\
\hline Women & 18.6 & 12.2 \\
\hline \multicolumn{3}{|l|}{ Race/ethnicity } \\
\hline White & 64.5 & 60.5 \\
\hline Black & 20.8 & 23.3 \\
\hline Hispanic & 8.8 & 9.9 \\
\hline Other & 6.0 & 6.3 \\
\hline \multicolumn{3}{|l|}{ Education $^{c}$} \\
\hline$\leq$ High school & 97.3 & 97.3 \\
\hline$>$ High school & 2.7 & 2.7 \\
\hline \multicolumn{3}{|l|}{ Marital status ${ }^{c}$} \\
\hline Married & 32.0 & 32.1 \\
\hline Unmarried & 68.0 & 67.9 \\
\hline \multicolumn{3}{|l|}{ Pay grade ${ }^{c}$} \\
\hline E1-E3 & 61.3 & 60.4 \\
\hline E4-E6 & 24.7 & 26.3 \\
\hline E7-E9 & 3.0 & 1.8 \\
\hline Officers & 11.0 & 11.4 \\
\hline \multicolumn{3}{|c|}{ Duration active duty follow-up (years) } \\
\hline Mean (SD) & $3.0(2.5)$ & $5.4(2.3)$ \\
\hline \multicolumn{3}{|l|}{ Duration of service (years) } \\
\hline Mean (SD) & $6.3(6.6)$ & $8.4(6.3)$ \\
\hline \multicolumn{3}{|l|}{ Hostile fire pay } \\
\hline Ever & 27.6 & 79.8 \\
\hline Never & 72.4 & 20.3 \\
\hline \multicolumn{3}{|l|}{ Major command code $\mathrm{c}^{\mathrm{c}}$} \\
\hline U.S. Army Forces Command & 22.5 & 25.3 \\
\hline Training and Doctrine & 49.5 & 49.8 \\
\hline V Corps (Europe) & 4.9 & 5.1 \\
\hline Medical Command & 5.8 & 3.7 \\
\hline 8th U.S. Army & 2.9 & 3.6 \\
\hline U.S. Army Pacific & 2.6 & 1.7 \\
\hline Special Operations & 1.3 & 1.9 \\
\hline Signal Command & 0.9 & 0.7 \\
\hline Intelligence and Security & 0.9 & 0.5 \\
\hline Other & 8.9 & 7.7 \\
\hline \multicolumn{3}{|l|}{ Year follow-up ended } \\
\hline$<1999$ & 12.7 & 0.2 \\
\hline 1999 & 9.4 & 2.1 \\
\hline 2000 & 8.7 & 3.0 \\
\hline 2001 & 8.8 & 3.7 \\
\hline 2002 & 8.6 & 2.7 \\
\hline 2003 & 6.5 & 4.7 \\
\hline 2004 & 5.5 & 7.6 \\
\hline 2005 & 40.0 & 76.1 \\
\hline
\end{tabular}

a APDA cases: Soldiers determined disabled during Active Duty by the Army Physical Disability Agency.

b Veterans without disability and with known date of separation from the Army.

c Assessed at the beginning of follow-up.

d Includes Warrant and Commissioned officers.

hostile fire pay (Table $4 \mathrm{~b}$ ). The proportion of persons vaccinated among those receiving hostile fire pay appears to increase with more recent date of separation from military service (Tables $4 \mathrm{a}$ and $4 \mathrm{~b}$ ). A similar trend is not apparent between recent date of separation and probability of vaccination among persons who did not receive hostile fire pay.

After adjustment for covariates, Veterans who had been vaccinated against anthrax had lower odds of later receiving VBA benefits compared to those who had not been vaccinated (Table 5). Odds of non-traumatic disabilities and disability ratings of $\geq 10 \%$ and $20 \%$ were $5 \%, 4 \%$, and $19 \%$ lower, respectively, among those with a history of anthrax vaccination compared to those unvaccinated. The odds of musculoskeletal disability and ratings above $20 \%$ were not associated with prior vaccination among Veterans receiving VBA benefits. There was no association between prior vaccination against anthrax and odds of disability separation from the Army, overall or due to musculoskeletal or non-traumatic causes. Odds of being rated 20\% disabled were lower among those with prior vaccination, but other levels of disability ( $\geq 10 \%,>20 \%$ ) were not associated with vaccination status (Table 5).

Goodness of fit testing for the final models shown in Table 5 indicated differences between the VBA and APDA case series. Using variables recorded during Active Duty provided a model that discriminated well between VBA cases and controls $(c=0.73)$, but showed statistically significant lack of fit $(p<0.001$ for the Hosmer-Lemeshow test). The final model for the APDA case series had adequate fit $(p=0.38)$, and the $c$-statistic for discrimination between cases and controls was 0.66 .

To examine possible interactions, we stratified logistic regression models by receipt of HFP(Table 6 ). Among those with no record of HFP, AVA was associated with a $5 \%$ overall lower odds of receiving VBA benefits after separation from the Army, but associations varied depending on disability outcome. AVA was positively associated with odds of musculoskeletal and non-traumatic disabilities and $a \geq 10 \%$ rating. Odds of more severe disability ratings were slightly elevated and marginally statistically significant (Table 6). In contrast, among Veterans receiving VBA disability benefits who had received HFP while on Active Duty, the adjusted odds of disability, overall and within any category of disability type or severity, were reduced by $20 \%$ to nearly $40 \%$ among those vaccinated during Active Duty (Table 6).

Prior anthrax vaccination was not associated overall with separation from the Army for disability among Soldiers without HFP records (APDA cases) (Table 6). The associations between prior anthrax vaccination and odds of musculoskeletal disability, nontraumatic disability, and a $>20 \%$ disability rating were similarly not significant. AVA was associated with lower odds of receiving an ADPA disability rating of $20 \%$ but slightly higher odds of receiving a $10 \%$ disability rating. As was seen for the VBA analysis, Soldiers with HFP and prior AVA had significantly lower odds of ADPA disability for all categories except $10 \%$ ratings (Table 6 ).

The results in Table 6 were derived from models developed individually for each of the strata using the methods previously described; these led to different model covariates as described in the footnotes to Table 6 . The VBA cases-no HFP best fitting models (Table 6) shows an overall lower risk of disability, while elevated risks are seen when the outcome is subdivided into type or degree of disability (musculoskeletal, non-traumatic, 10\%, 20\%, >20\%). To further explore these anomalous results, we re-ran these models using the same covariates included in the overall (disability yes/no) model (Table 6, same covariates as all disabilities model). In this re-analysis, the odds ratios within each disability outcome stratum were mainly in agreement, with a negative association between AVA and the outcome seen in 9 of 10 comparisons, and a positive association for musculoskeletal disability among those not receiving HFP. This was the smallest disability category and comprised only $5 \%$ of all Veterans receiving VBA benefits.

\section{Discussion}

These analyses demonstrate no overall increase in risk of disability associated with AVA for cases identified by the Army (APDA cases) or the VBA. The results for APDA case series are generally consistent with those of a previous cohort analysis that included up to six years of follow-up from first dose of AVA and showed no contribution of anthrax vaccination to risk of APDA disability evaluation or separation from the Army [19]. The models predicting receipt of VBA benefits show overall reduced risk for Veterans who received AVA during Active Duty compared to those who did not. 
Table 4a

Hostile fire pay by year of separation from Service, disability.

\begin{tabular}{|c|c|c|c|c|}
\hline \multirow{3}{*}{$\begin{array}{l}\text { A: VBA cases and controls }{ }^{\mathrm{a}, \mathrm{b}} \\
\text { Date of separation }\end{array}$} & \multicolumn{4}{|c|}{ Number of soldiers (\%) } \\
\hline & \multicolumn{2}{|c|}{ Ever received hostile fire pay } & \multicolumn{2}{|c|}{ Never received hostile fire pay } \\
\hline & Disabled & Not disabled & Disabled & Not disabled \\
\hline Up to 1999 & $1471(18.5)$ & $6467(81.5)$ & $15,493(24.6)$ & $47,510(75.4)$ \\
\hline $1999-2000$ & $2230(20.0)$ & $8944(80.0)$ & $12,732(25.2)$ & $37,779(74.8)$ \\
\hline 2000-2001 & $3224(23.0)$ & $10,806(77.0)$ & $12,075(25.0)$ & $36,331(75.0)$ \\
\hline 2001-2002 & $3848(24.1)$ & $12,132(75.9)$ & $12,348(24.6)$ & $37,932(75.4)$ \\
\hline $2002-2003$ & $4037(27.5)$ & $10,643(72.5)$ & $11,197(24.2)$ & $34,974(75.8)$ \\
\hline $2003-2004$ & $6153(27.6)$ & $16,180(72.4)$ & $9715(25.9)$ & $27,845(74.1)$ \\
\hline 2004-2005 & $12,517(31.9)$ & $26,732(68.1)$ & $8993(27.8)$ & $23,309(72.2)$ \\
\hline $2005-2006$ & $12,367(29.2)$ & $29,950(70.8)$ & $6817(26.3)$ & $19,077(73.7)$ \\
\hline $2006+$ & $9394(3.2)$ & $283,273(96.8)$ & $4323(4.6)$ & $113,041(96.3)$ \\
\hline \multicolumn{5}{|l|}{ B: APDA cases and controls ${ }^{\mathrm{b}, \mathrm{c}}$} \\
\hline Up to 1999 & $29(1.4)$ & $6467(98.6)$ & $495(1.0)$ & $47,510(90.0)$ \\
\hline $1999-2000$ & $85(1.0)$ & $8944(99.1)$ & $674(1.7)$ & $37,779(98.3)$ \\
\hline $2000-2001$ & $132(1.2)$ & $10,806(98.8)$ & $585(1.6)$ & $36,331(98.4)$ \\
\hline 2001-2002 & $124(1.0)$ & $12,132(99.0)$ & $456(1.2)$ & $37,932(98.8)$ \\
\hline $2002-2003$ & $96(0.9)$ & $10,643(99.1)$ & $339(1.0)$ & $34,974(99.0)$ \\
\hline 2003-2004 & $141(0.9)$ & $16,180(99.1)$ & $300(1.1)$ & $27,845(98.9)$ \\
\hline 2004-2005 & $204(0.8)$ & $26,732(99.2)$ & $374(1.6)$ & $23,309(98.4)$ \\
\hline $2005-2006$ & $505(1.7)$ & $29,950(98.3)$ & $463(2.4)$ & $19,077(97.6)$ \\
\hline $2006+$ & $517(0.2)$ & $283,273(99.8)$ & $327(0.3)$ & 113,041 (99.7) \\
\hline
\end{tabular}

a VBA cases: Veterans receiving benefits from the Veterans Benefits Administration as of February 2007.

b Veterans without disability and with known date of separation from the Army.

c APDA cases: Soldiers determined disabled during Active Duty by the Army Physical Disability Agency.

The timing of disability determination and the case-defining criteria used by the two agencies differ. The VBA grants benefits to Veterans who have disabling conditions caused or worsened by Service $^{\mathrm{a}}$, whereas the APDA determines disability based on ability to meet duty requirements. Two observations suggest these differences in case ascertainment methods are meaningful: 1. The association between AVA during Active Duty and subsequent disability status is null for APDA cases but negative for VBA cases; and 2. Models using factors identified during Active Duty provided adequate goodness of fit for the APDA analyses, but not the VBA analyses. Discrimination was adequate for both models.

For both the VBA and APDA case series, receipt of HFP was associated with a reduction in odds of disability. Among those without HFP records, the results generally showed null associations or small magnitude increases in odds of disability as determined by both the VBA and the Army. Because there is no reason to expect AVA to have different biological effects, i.e., raising the risk of disability for one group and lowering the risk for the other group, the most plausible interpretation of these results, given the overall negative associations between disability and AVA, is that they reflect selection or other residual confounding. For example, deployed personnel were subject to higher standards for health and fitness compared with non-deployed Soldiers. We suspect this "Healthy Warrior Effect" [20] explains the lower risks of disability associated with vaccination status for those who enlisted prior to 2000 and for those with HFP records [20]. The finding of a possible increase in musculoskeletal outcomes among those who did not receive HFP in both the best fitting and same covariates models (Table 6) is unlikely:

Table 4b

Hostile fire pay by year of separation from Service, vaccination status.

\begin{tabular}{|c|c|c|c|c|}
\hline \multirow{3}{*}{$\begin{array}{l}\text { A: VBA cases and controls }{ }^{\mathrm{a}, \mathrm{b}} \\
\text { Date of separation }\end{array}$} & \multicolumn{4}{|c|}{ Number of soldiers (\%) } \\
\hline & \multicolumn{2}{|c|}{ Ever received hostile fire pay } & \multicolumn{2}{|c|}{ Never received hostile fire pay } \\
\hline & Vaccinated & Not vaccinated & Vaccinated & Not vaccinated \\
\hline Up to 1999 & $689(8.7)$ & $7249(91.3)$ & $287(0.5)$ & $62,716(99.5)$ \\
\hline 1999-2000 & $3020(27.0)$ & $8154(73.0)$ & $5925(11.7)$ & $44,586(88.3)$ \\
\hline 2000-2001 & $4574(32.6)$ & $9456(67.4)$ & $9581(19.8)$ & $38,825(80.2)$ \\
\hline 2001-2002 & $5796(36.3)$ & $10,184(63.7)$ & $11,664(23.2)$ & $38,616(76.8)$ \\
\hline 2002-2003 & $5182(35.3)$ & $9498(64.7)$ & $8619(18.7)$ & $37,552(81.3)$ \\
\hline $2003-2004$ & $13,469(60.3)$ & $8864(39.7)$ & $9605(25.6)$ & $27,995(74.4)$ \\
\hline 2004-2005 & $31,888(81.2)$ & $7361(18.8)$ & $7669(23.7)$ & $24,633(76.3)$ \\
\hline 2006-2006 & $36,263(85.7)$ & $6054(14.3)$ & $6179(23.9)$ & $19,715(76.1)$ \\
\hline $2006+$ & $222,425(76.0)$ & $70,242(24.0)$ & $31,691(27.0)$ & $85,673(73.0)$ \\
\hline \multicolumn{5}{|l|}{ B: APDA cases and controls ${ }^{b, c}$} \\
\hline Up to 1999 & $599(9.2)$ & $5897(90.8)$ & $251(0.5)$ & $47,754(99.5)$ \\
\hline 1999-2000 & $2469(27.3)$ & $6560(72.7)$ & 4952(12.9) & $33,501(87.1)$ \\
\hline 2000-2001 & $3577(32.7)$ & $7361(67.3)$ & $7424(20.1)$ & $29,492(79.9)$ \\
\hline $2001-2002$ & $4563(37.2)$ & $7693(62.8)$ & $8810(23.0)$ & $29,578(77.0)$ \\
\hline 2002-2003 & $3808(35.5)$ & $6931(64.5)$ & $5835(16.5)$ & $29,478(83.5)$ \\
\hline 2003-2004 & $10,060(61.6)$ & $6261(38.4)$ & $6716(23.9)$ & $21,429(76.1)$ \\
\hline 2004-2005 & $22,421(83.5)$ & $4515(16.8)$ & $4928(20.8)$ & $18,755(79.2)$ \\
\hline 2006-2006 & $26,637(87.5)$ & $3818(12.5)$ & $4212(21.6)$ & $15,328(78.4)$ \\
\hline $2006+$ & $215,335(75.9)$ & $68,455(24.1)$ & $30,378(26.8)$ & $82,990(73.2)$ \\
\hline
\end{tabular}

a VBA cases: Veterans receiving benefits from the Veterans Benefits Administration as of February 2007.

b Veterans without disability and with known date of separation from the Army.

c APDA cases: Soldiers determined disabled during Active Duty by the Army Physical Disability Agency. 
Table 5

Case and control counts (percents) and adjusted odds ratios (95\% confidence intervals) for disability.

\begin{tabular}{|c|c|c|}
\hline & $N(\%)$ & OR (95\% confidence interval) \\
\hline \multicolumn{3}{|l|}{ 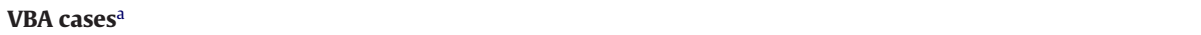 } \\
\hline All disabilities ${ }^{b}$ & 148,934 & $0.79(0.78-0.80)$ \\
\hline Musculoskeletale,f & 7351 & $0.98(0.92,1.04)$ \\
\hline Non-traumatic ${ }^{\mathrm{e}, \mathrm{f}}$ & 65,224 & $0.95(0.93,0.97)$ \\
\hline Disability $10 \%$ e,f & $90,584\left(60.8^{\mathrm{d}}\right)$ & $0.96(0.94,0.98)$ \\
\hline Disability $20 \%$ e,f & $21,154\left(14.2^{\mathrm{d}}\right)$ & $0.81(0.79,0.84)$ \\
\hline Disability $>20 \%$ e,f & $37,196\left(25.0^{\mathrm{d}}\right)$ & $0.98(0.96,1.01)$ \\
\hline \multicolumn{3}{|l|}{ APDA cases $^{\mathrm{a}}$} \\
\hline All disabilities ${ }^{c}$ & 5846 & $0.98(0.92,1.05)$ \\
\hline Musculoskeletal $^{\mathrm{e}}$ & 3924 & $0.94(0.87,1.02)$ \\
\hline Non-traumatic ${ }^{\mathrm{e}}$ & 4693 & $0.94(0.87,1.01)$ \\
\hline Disability $10 \%$ & $4140(70.8)$ & $1.05(0.97,1.14)$ \\
\hline Disability $20 \%$ e & $690(11.8)$ & $0.70(0.57,0.85)$ \\
\hline Disability $>20 \%{ }^{\mathrm{e}}$ & $1016(17.4)$ & $0.91(0.78,1.06)$ \\
\hline Controls ${ }^{\mathrm{a}}$ & 782,925 & 1.0 \\
\hline
\end{tabular}

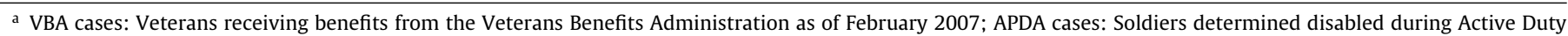

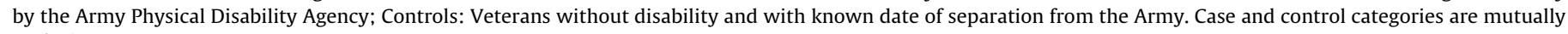
exclusive.

b Adjusted for gender, age, race/ethnicity, duration of service, hostile fire pay, major command code, and ever served abroad (yes/no).

c Adjusted for gender, age, race/ethnicity, pay grade, hostile fire pay, major command code, and ever served abroad (yes/no).

d Percent of disabilities within category (column percent).

e Model does not include major command code.

${ }^{\mathrm{f}}$ Based on primary reason for disability and Veteran's System for Rating Disabilities code.

there was no positive association between musculoskeletal disability and vaccination among subjects who did receive HFP, and in fact the association in this group was significantly negative. The plausibility of a causal association that is protective in one group and not in the other is low. Furthermore, the number of sub-group comparisons raises the likelihood of false positive associations in either direction.

Most previous studies of adverse vaccine effects in the Military evaluated the experiences of Active Duty personnel, which constrained inquiry to short-term adverse events [8]. A subset of those previous studies additionally employed data from passive surveillance systems, which, while useful for generating hypotheses, cannot be used to test whether reported adverse events are associated with the purported exposure because of the high likelihood of incomplete or biased case ascertainment [7].

To improve completeness and reduce the likelihood of biased reporting, we analyzed data originally collected for administrative purposes by both the Army and the VBA. Two-thirds of the cases included in this study were identified by the VBA but not the APDA; finding cases in the VBA system may thus provide a more

\section{Table 6}

Case and control counts (percents) and adjusted ${ }^{\mathrm{a}}$ odds ratios (95\% confidence intervals) for disability, by receipt of hostile fire pay.

\begin{tabular}{|c|c|c|c|c|c|c|}
\hline & \multicolumn{3}{|l|}{ No hostile fire pay } & \multicolumn{3}{|l|}{ Hostile fire pay } \\
\hline & $N(\%)$ & $\begin{array}{l}\text { Best fitting } \\
\text { models }\end{array}$ & $\begin{array}{l}\text { Same covariates as } \\
\text { all disabilities } \\
\text { model }\end{array}$ & $N(\%)$ & $\begin{array}{l}\text { Best fitting } \\
\text { models }\end{array}$ & $\begin{array}{l}\text { Same covariates as } \\
\text { all disabilities } \\
\text { model }\end{array}$ \\
\hline & & $\begin{array}{l}\text { OR ( } 95 \% \text { confidence } \\
\text { interval) }\end{array}$ & $\begin{array}{l}\text { OR }(95 \% \text { confidence } \\
\text { interval })^{\mathrm{b}}\end{array}$ & & $\begin{array}{l}\text { OR ( } 95 \% \text { confidence } \\
\text { interval) }\end{array}$ & $\begin{array}{l}\text { OR }(95 \% \text { confidence } \\
\text { interval })^{\mathrm{b}}\end{array}$ \\
\hline \multicolumn{7}{|l|}{ VBA cases ${ }^{\mathrm{a}}$} \\
\hline All disabilities ${ }^{\mathrm{b}}$ & $93,693\left(62.9^{9}\right)$ & $0.95(0.93,0.97)$ & $0.95(0.93,0.97)$ & $55,241\left(37.1^{g}\right)$ & $0.66(0.65,0.67)$ & $0.66(0.65,0.67)$ \\
\hline Musculoskeletal ${ }^{\mathrm{e}, \mathrm{f}}$ & 5675 & $1.18(1.10,1.27)$ & $1.23(1.15,1.33)$ & 1676 & $0.73(0.66,0.80)$ & $0.72(0.65,0.80)$ \\
\hline Non-traumatic ${ }^{\mathrm{e}, \mathrm{f}}$ & 40,769 & $1.07(1.04,1.10)$ & $0.90(0.88,0.93)$ & 24,455 & $0.81(0.78,0.83)$ & $0.68(0.66,0.70)$ \\
\hline Disability $10 \%$ e,f & $56,029\left(59.8^{\mathrm{d}}\right)$ & $1.16(1.13,1.19)$ & $0.97(0.95,1.00)$ & $34,555\left(67.6^{\mathrm{d}}\right)$ & $0.78(0.77,0.80)$ & $0.65(0.63,0.66)$ \\
\hline Disability $20 \%$ e,f & $14,120\left(15.1^{\mathrm{d}}\right)$ & $1.04(0.99,1.09)$ & $0.86(0.82,0.90)$ & $7034\left(12.7^{\mathrm{d}}\right)$ & $0.62(0.59,0.65)$ & $0.51(0.49,0.54)$ \\
\hline Disability > 20\%e,f & $23,544\left(25.1^{\mathrm{d}}\right)$ & $1.04(1.00,1.08)$ & $0.88(0.85,0.92)$ & $13,652\left(24.7^{\mathrm{d}}\right)$ & $0.88(0.85,0.91)$ & $0.76(0.73,0.79)$ \\
\hline \multicolumn{7}{|l|}{ APDA cases $^{\mathrm{a}}$} \\
\hline All disabilities ${ }^{c}$ & $4013(68.6)$ & $1.05(0.96,1.14)$ & & $1833(31.4)$ & $0.89(0.80,0.98)$ & \\
\hline Musculoskeletal & 2772 & $1.06(0.96,1.18)$ & & 1152 & $0.81(0.71,0.91)$ & \\
\hline Non-traumatic ${ }^{\mathrm{e}}$ & 3308 & $1.01(0.92,1.11)$ & & 1385 & $0.83(0.74,0.93)$ & \\
\hline Disability $10 \%$ & $2865(71.4)$ & $1.12(1.01,1.23)$ & & $1275(69.6)$ & $0.97(0.86,1.09)$ & \\
\hline Disability $20 \%$ & $507(12.6)$ & $0.66(0.50,0.87)$ & & $183(10.0)$ & $0.72(0.50,0.98)$ & \\
\hline Disability $>20 \%$ e & $641(16.0)$ & $1.11(0.91,1.37)$ & & $375(20.4)$ & $0.69(0.56,0.85)$ & \\
\hline Controls $^{\mathrm{a}}$ & $377,798\left(48.3^{\mathrm{c}}\right)$ & 1.0 & & $405,127\left(51.7^{c}\right)$ & 1.0 & \\
\hline
\end{tabular}

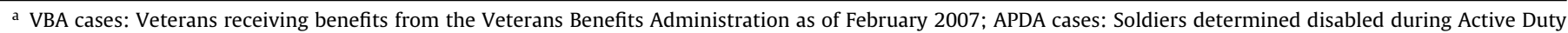

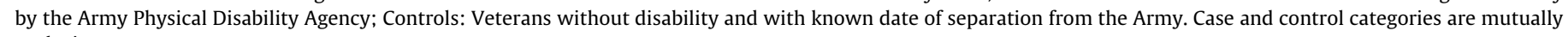
exclusive.

b Adjusted for gender, age, race/ethnicity, duration of service, major command code, and ever served abroad (yes/no).

c Adjusted for gender, age, race/ethnicity, pay grade, major command code, and ever served abroad (yes/no).

d Percent of disabilities within category (column percent).

e Model does not include major command code.

f Based on primary reason for disability and Veteran's System for Rating Disabilities code.

g Percent with and without HFP (row percent). 
sensitive indicator, casting a "broader net" than using only APDA data. We hypothesized that disabilities identified in the VBA system might additionally represent more severe or longer-lasting conditions than those identified by the APDA, and indeed found a higher proportion of VBA cases to be at least $20 \%$ disabled compared to APDA cases (25\% versus 16\%). Because the VBA captures disability ratings independent of choice or usage of health care facilities, it is less likely that this study suffers from biased case finding or underreporting than if clinical contact in a particular health care system had been required to capture outcomes.

Others have found that the likelihood of spontaneously reporting a potential vaccine-related adverse event is several-fold lower in Military compared to civilian populations, and that both the severity of the event and its likelihood of being causally associated with vaccine were higher for Military compared to civilian vaccinates [21]. On the other hand, use of administrative data for research purposes is associated with its own limitations. The VBA file we used represents a "snapshot" of all veterans with a disability rating and receiving compensation as of April 2007, 2.5 years after the end of the study as originally designed. It was not possible to capture the dates on which disabilities were determined, so we could not account for follow-up time. The VASRD codes used by both the VBA and the APDA group outcomes into broad categories of reasons for disability, potentially introducing error in choosing which outcomes were plausibly related to AVA. It is also not possible to validate the reasons for disability assigned to individual Veterans.

\section{Conclusions}

Using cases identified from both VBA and APDA files, we found no overall higher risk of objectively assessed disability status with receipt of AVA. VBA data did not show any consistent statistically significant associations between vaccine exposure and subsequent disability, and for most comparisons showed lower odds of disability. AVA was associated with reduced risk of overall disability among those with HFP records and among VBA cases without HFP. Among APDA cases without HFP, vaccination was associated with a small non-significant increase in risk of disability overall, and a statistically significant $12 \%$ higher odds of $10 \%$ disability and a $34 \%$ lower odds of $20 \%$ disability, suggesting likely type 1 errors due to multiple testing. There were also small magnitude increases in odds of certain categories of disability associated with AVA for VBA cases without HFP, although this appeared to be dependent on the strategy used to build the regression models, with the same covariates model showing mainly lower odds of disability depending on the outcome stratum. Furthermore, the VBA model demonstrated lack of fit. Statistically significant reductions in odds of disability associated with vaccination among those with HFP records is more likely due to selection bias (the "Healthy Warrior Effect") arising from pre-deployment health screening than a true protective effect. This study supports our previous analyses of Army disability experiences, and provides additional evidence that the AVA is not associated with adverse outcomes as captured by the VBA and APDA databases.

\section{Acknowledgements}

Funding for this work was provided by the US Department of the Army, contract number W911QY-06-P-0337. This material is the result of work supported in part by resources from the VA Puget Sound Health Care System, Seattle, Washington. Dr. Sulsky had full access to all of the data in the study and takes responsibility for the integrity of the data and the accuracy of the data analysis. Drs. Amoroso, Boyko and Maynard contributed to the study design. All authors contributed to the analysis and interpretation of the results and provided critical review and editing of the manuscript. VA Puget Sound supported Drs. Boyko and Maynard's involvement in this research.

The authors are grateful to Mr. Jeffrey Williams and Ms. Lauren Komp for producing the analytical data sets and for their able management of the TAIHOD, and to Ms. Sima Blank for her technical assistance.

\section{References}

[1] Riedel S. Anthrax: a continuing concern in the era of bioterrorism. Proc (Bayl Univ Med Cent) 2005;18(3):234-43.

[2] Grabenstein JD, Winkenwerder Jr W. Bioterrorism and compulsory vaccination: United States continues vaccinating to keep troops healthy. BMJ 2004;329(7472):977.

[3] Sever JL, Brenner AI, Gale AD, Lyle JM, Moulton LH, Ward BJ, West DJ. Safety of anthrax vaccine: an expanded review and evaluation of adverse events reported to the Vaccine Adverse Event Reporting System (VAERS). Pharmacoepidemiol Drug Saf 2004;13(12):825-40.

[4] U.S.Department of Defense. Anthrax Vaccine Immunization Program. http://www anthrax osd mil/2007 [cited 2007]; available from: URL: http://www.anthrax.osd.mil/.

[5] McNeil MM, Chiang IS, Wheeling JT, Zhang Y. Short-term reactogenicity and gender effect of anthrax vaccine: analysis of a 1967-1972 study and review of the 1955-2005 medical literature. Pharmacoepidemiol Drug Saf 2007; 16(3):259-74.

[6] Centers for Disease Control. Surveillance for adverse events associated with anthrax vaccination - U.S. Department of Defense, 1998-2000. MMWR Morb Mortal Wkly Rep 2000;49(16):341-5.

[7] Niu MT, Ball R, Woo EJ, Burwen DR, Knippen M, Braun MM. Adverse events after anthrax vaccination reported to the Vaccine Adverse Event Reporting System (VAERS), 1990-2007. Vaccine 2009;27(January (2)):290-7.

[8] Institute of Medicine. The Anthrax Vaccine: Is it safe? Does it work? Washington DC: National Academy Press; 2002.

[9] Sulsky SI, Grabenstein JD, Delbos RG. Disability among U. S. army personnel vaccinated against anthrax. JOEM 2004;46(10):1065-75.

[10] Smith B, Leard CA, Smith TC, Reed RJ, Ryan MA. Anthrax vaccination in the Millennium Cohort: validation and measures of health. Am J Prev Med 2007;32(4):347-53.

[11] Ryan MA, Smith TC, Sevick CJ, Honner WK, Loach RA, Moore CA, Erickson JD. Birth defects among infants born to women who received anthrax vaccine in pregnancy. Am J Epidemiol 2008;168(August (4)):434-42.

[12] Downing J, Greig TW, Quattlebaum MD, Valentin M, Heeren TC, Grabenstein JD. Assessing the safety of anthrax immunization in US Army aircrew members via physical examination. J Occup Environ Med 2007;49(10):1079-85.

[13] Wiesen AR, Littell CT. Relationship between prepregnancy anthrax vaccination and pregnancy and birth outcomes among US Army women. JAMA 2002;287(12):1556-60.

[14] Hambleton P, Carman JA, Melling J. Anthrax: the disease in relation to vaccines. Vaccine 1984;2(2):125-32.

[15] Demicheli V, Rivetti D, Deeks JJ, Jefferson T, Pratt M. The effectiveness and safety of vaccines against human anthrax: a systematic review. Vaccine 1998;16(9-10):880-4.

[16] Carpenter DO. Environmental contaminants as risk factors for developing diabetes. Rev Environ Health 2008;23(1):59-75.

[17] Amoroso PJ. Total Army injury and health outcomes database: a model comprehensive research database. Mil Med 1999.

[18] Statistical Analysis System Version 9.1 [computer program]. Version 9.1. Cary, NC, USA: SAS Institute Inc., 2003.

[19] Sulsky SI, Luippold RS, Garman P, Hughes H, Amoroso PJ. Risk of disability for US army personnel vaccinated against anthrax, 1998-2005. Vaccine 2011;29(August (35)):6035-41.

[20] Haley RW. Point: bias from the healthy-warrior effect and unequal follow-up in three government studies of health effects of the Gulf War. Am J Epidemiol 1998;148(August (4)):315-23.

[21] McMahon AW, Zinderman C, Ball R, Gupta G, Braun MM. Comparison of military and civilian reporting rates for smallpox vaccine adverse events. Pharmacoepidemiol Drug Saf 2007;16(June (6)):597-604. 